\title{
Reactivity and Reusability of Mesoporous Alumina Nanoparticles Modified with Sulfuric Acid and Niobic Acid in the Alkylation of Resorcinol
}

\author{
Sheela Chandren ${ }^{\mathrm{a}}$, Zainab Ramli ${ }^{\mathrm{b}, *}$ and Hadi Nur ${ }^{\mathrm{b}}$ \\ ${ }^{a}$ Department of Chemistry, Faculty of Science, Universiti Teknologi Malaysia, 81310 Skudai, Johor. \\ ${ }^{b}$ Ibnu Sina of Institute for Fundamental Studies, Universiti Teknologi Malaysia, 81310 Skudai, Johor. \\ *To whom correspondence should be addressed. E-mail: zainab@kimia.fs.utm.my
}

Received 2 February 2008

http://dx.doi.org/10.11113/mjfas.v4n1.39

\section{ABSTRACT}

With the development of large molecule hydrocarbon processes, mesoporous alumina which possesses high surface area with narrow pore size distribution has received a great deal of attention. However, its acid properties lack Bronsted acidity and showed only Lewis acid sites, making it an inactive solid catalyst in the alkylation of resorcinol, a reaction which requires the usage of solid acid catalysts with both Bronsted and Lewis acidity. In this study, in order to introduce Bronsted acidity to mesoporous alumina, sulfuric acid $\left(\mathrm{H}_{2} \mathrm{SO}_{4}\right)$ and niobic acid $\left(\mathrm{Nb}_{2} \mathrm{O}_{5} \cdot \mathrm{nH}_{2} \mathrm{O}\right)$ are introduced to the alumina. The reactivity of mesoporous alumina nanoparticles (MAN), $\mathrm{Nb}_{2} \mathrm{O}_{5} \cdot \mathrm{nH}_{2} \mathrm{O} / \mathrm{MAN}$ and $\mathrm{H}_{2} \mathrm{SO}_{4} / \mathrm{MAN}$ were tested out on the alkylation of resorcinol with methyl tert-butyl ether. No product was obtained using pure MAN, while both $\mathrm{H}_{2} \mathrm{SO}_{4} / \mathrm{MAN}$ and $\mathrm{Nb}_{2} \mathrm{O}_{5} \cdot \mathrm{nH}_{2} \mathrm{O} / \mathrm{MAN}$ managed to produce butylated resorcinol. Mesoporous alumina nanoparticles incorporated with sulfuric acid produced a greater amount of dibutylated resorcinol, which theoretically is a better antioxidant compared to monobutylated resorcinol. The reusability of the $\mathrm{H}_{2} \mathrm{SO}_{4} / \mathrm{MAN}$ catalyst was also better as dibutylated product was still obtained even in the second use. This indicates that sulfuric acid has created a more stable and also higher strength of Bronsted acidity in alumina as compared to niobic acid.

| Mesoporous alumina | Sulfuric acid | niobic acid | alkylation of resorcinol |

\section{Introduction and Preliminaries}

Friedel-Crafts reactions are of considerable importance in the productions of fine chemicals [1]. Many industrial processes for the production of pharmaceutical products, fragrances, antioxidant, paint additives, cosmetics and others involve an intermediate step that is the Friedel-Crafts reaction. This type of reaction requires the present of acidic catalyst in order to allow the reaction to proceed at a convenient rate. Unfortunately, the use of homogenous conventional Lewis and Bronsted acid catalyst such as $\mathrm{AlCl}_{3}, \mathrm{BF}_{3}$, $\mathrm{FeCl}_{3}, \mathrm{ZnCl}_{2}, \mathrm{H}_{2} \mathrm{SO}_{4}, \mathrm{HCl}$ and $\mathrm{HF}$ lead to several problems such as they need more than stoichiometric amount because of complexation of reactant or product, disposal of potentially highly polluting and toxic wastes and corrosiveness [2]. Homogeneous catalysts also involve problems in products separation as the catalyst is in the same phase with the products.

Mesoporous alumina is an interesting material with a high surface area and a narrow pore size distribution in a mesopore region, and has been synthesized using various templates such as polyethylene 
oxides, carboxylic acids and tetraalkylammonium salts [3]. While mesoporous alumina has found it successful application as a catalytic material in a number of reactions involving epoxidation of olefins, hydrodechlorination, hydrodesulfurization, olefin methathesis, oxidation of methane to syngas, and oxidative dehydrogenation of ethane, the utility of mesoporous alumina as a solid catalyst in Friedel-Crafts alkylations is hindered by the existence of Lewis acidity only and the lack of Bronsted acid sites.

In this paper, in order to introduce Bronsted acidity to mesoporous alumina, sulfuric acid $\left(\mathrm{H}_{2} \mathrm{SO}_{4}\right)$ and niobic acid $\left(\mathrm{Nb}_{2} \mathrm{O}_{5} \cdot \mathrm{nH}_{2} \mathrm{O}\right)$ are introduced to the alumina. The reactivity of mesoporous alumina nanoparticles (MAN), $\mathrm{H}_{2} \mathrm{SO}_{4} / \mathrm{MAN}$ and $\mathrm{Nb}_{2} \mathrm{O}_{5} \cdot \mathrm{nH}_{2} \mathrm{O} / \mathrm{MAN}$ are tested out on the alkylation of resorcinol with methyl tert-butyl ether.

\section{Materials and Methods}

\subsection{Preparation of the Mesoporous Alumina Catalysts}

The mesoporous alumina nanoparticles were prepared from gels with the following molar composition:

$$
1 \mathrm{Al}\left(\mathrm{C}_{3} \mathrm{H}_{7} \mathrm{O}\right)_{3}: 0.3 \mathrm{CTABr}: 1.8 \mathrm{HCl}: 17 \mathrm{C}_{3} \mathrm{H}_{7} \mathrm{OH}: 22 \mathrm{H}_{2} \mathrm{O}
$$

The procedure compromises of three steps. Firstly, the hydrolysis of aluminum iso-propoxide $\left(\mathrm{Al}\left(\mathrm{C}_{3} \mathrm{H}_{7} \mathrm{O}\right)_{3}\right.$, Merck, 98\%) by hydrochloric acid ( $\mathrm{HCl}$, Merck, 37\%) at room temperature was carried out for $4 \mathrm{~h}$ in the presence of the surfactant cetyltrimethylammonium bromide (CTABr; 99\% Fluka) and iso-propanol $\left(\mathrm{C}_{3} \mathrm{H}_{7} \mathrm{OH}\right.$, Fluka, 99\%). The second step was the condensation of aluminum hydrolyzed species by heating the reacting mixture at $80{ }^{\circ} \mathrm{C}$. Then the sol gel obtained underwent ultrasonic treatment for 30 minutes in order to disperse the particles. Drying was then carried out at $100{ }^{\circ} \mathrm{C}$. Finally, the resulting material is calcined at $600{ }^{\circ} \mathrm{C}$ for $4 \mathrm{~h}$.

Sulfated mesoporous alumina samples were prepared according to the literature [6]. Four samples with different loading percentage of sulfate were prepared using sulfuric acid as the precursor. The desired amount of sulfuric acid was then added to toluene before adding the pre-dried MA ( $200^{\circ} \mathrm{C}$ for $\left.24 \mathrm{~h}\right)$. The mixture was stirred at $50^{\circ} \mathrm{C}$ for $1 \mathrm{~h}$ and dried at $130^{\circ} \mathrm{C}$ for $12 \mathrm{~h}$. The samples were designated as YS/MAN, with $\mathrm{Y}$ as the percentage of sulfate $\left(\mathrm{SO}_{4}{ }^{-2}\right)$ in wt\%.

Sample niobic acid on mesoporous alumina (NbA/MAN) with four different loadings of niobium were prepared by impregnation technique using niobium(V) ethoxide as the precursor as described in literature [5]. The needed amount of niobium(V) ethoxide was dissolved in iso-propanol to obtain the desired metal loading. Then, the required quantity of pre-dried MA $\left(200^{\circ} \mathrm{C}\right.$ for $\left.24 \mathrm{~h}\right)$ was immediately added to the clear solution with stirring. The mixture was stirred at room temperature for 3 hours before recovering the solid by evaporating the iso-propanol at $80^{\circ} \mathrm{C}$. The hydrolysis was then performed by adding $20 \mathrm{~mL} 0.5 \mathrm{M} \mathrm{HNO}_{3}$ in distilled water and aged overnight, followed by drying at $120^{\circ} \mathrm{C}$. The solid was washed with distilled water for three times and finally dried at $200^{\circ} \mathrm{C}$ for $24 \mathrm{~h}$. Sample denoted as XNbA/MAN, in which X is the percentage of the niobium in $\mathrm{wt} \%$

\subsection{Acidity Study}

About $20 \mathrm{mg}$ of sample was ground and pressed under 5 tons of pressure for 1 second in order to obtain 13 mm diameter of self-supporting wafer. The wafer was placed in the sample holder then put inside a homebuilt IR cell that consists of Pyrex glass and fitted with $\mathrm{CaF}_{2}$ window. Prior to the adsorption, samples were dehydrated under vacuum $\left(<10^{3} \mathrm{mbar}\right)$ at $400{ }^{\circ} \mathrm{C}(\mathrm{MAN})$ and $200{ }^{\circ} \mathrm{C}(\mathrm{S} / \mathrm{MAN}$ and NbA/MAN) for 16 hours. Acidity of the sample was determined by adsorption of pyridine (as probe molecule) on the evacuated sample at room temperature for a minute at 10 torr, followed by desorption of pyridine at $150{ }^{\circ} \mathrm{C}$ under vacuum for one hour. Infrared spectra of the pyridine vibration region were monitored in the range of $1700-1400 \mathrm{~cm}^{-1}$ in adsorbance mode, using Perkin Elmer Spectrum One FTIR Spectrometer. 


\subsection{Morphology Study}

Field Emission Scanning Electron Microscope (FESEM), Zeiss Supra Series model was used to determine the morphology of the samples.

\subsection{Catalytic Testing}

The catalysts performances were tested in the Friedel-Crafts alkylation reaction of resorcinol (SigmaAldrich, 99\%) with tert-butyl methyl ether (MTBE, Fischer, 99.8\%). Nitrobenzene (J.T. Baker, 99\%) was used as the internal standard. The reaction mixture containing resorcinol, MTBE and internal standard was placed in a round-bottom flask equipped with a condenser. About $0.2 \mathrm{~g}$ of the samples were activated for 4 hours and then added at once to the reaction mixture. Sample MAN was activated at $400{ }^{\circ} \mathrm{C}$, while samples $\mathrm{S} / \mathrm{MAN}$ and $\mathrm{NbA} / \mathrm{MAN}$ were activated at $200{ }^{\circ} \mathrm{C}$. The reaction was done under reflux in an oil bath with stirring using magnetic bar at $80{ }^{\circ} \mathrm{C}$ for 8 hours. The ratio of the resorcinol, MTBE and internal standard is $2: 3: 1$. For reusability test, the reaction condition for the first cycle is the same as described previously. However, for the subsequent runs the amount of substrates and solvent were scaled down according to the available amount of catalyst. The catalysts were filtered, washed with ethanol and reactivated before being used again. Products of reactions were separated and analysed using gas chromatography with FID detector using Ultra-1 column (length: 25 metres; internal diameter I.D: $0.2 \mathrm{~mm}$; film: $0.11 \mu \mathrm{m}$ ).

\section{Results and Discussion}

In the Friedel-Crafts alkylation of resorcinol with tert-butyl methyl ether, 4-tert-butylresorcinol and 4,6-di-tert-butylresorcinol were obtained as the major and minor products respectively. The results displayed in Table 1 shows that the alkylation of resorcinol with MTBE required the presence of a catalyst. This proved that without the presence of catalyst, the reaction did not produce any product because MTBE was not converted into the reactive species (electrophile). No product was obtained too when mesoporous alumina alone was used as the catalyst in the reaction. This indicates that the reaction needs the presence of Brønsted acid sites is necessary to initiate the reaction, as mesoporous alumina only possesses Lewis acidity as shown in the IR spectra in pyridine vibration region in Figure 1.

Table 1: Product yield obtained using mesoporous alumina nanoparticles modified with different Brønsted acid precursors

\begin{tabular}{lcccc}
\hline \multirow{2}{*}{ Catalyts } & \multicolumn{2}{c}{ 4-tertbutylresorcinol } & \multicolumn{2}{c}{ 4,6-di-tertbutylresorcinol } \\
\cline { 2 - 5 } & $\begin{array}{c}\text { Yield } \\
(\text { mmole })\end{array}$ & $\begin{array}{c}\text { Selectivity } \\
(\%)\end{array}$ & $\begin{array}{c}\text { Yield } \\
(\text { mmole })\end{array}$ & $\begin{array}{c}\text { Selectivity } \\
(\%)\end{array}$ \\
\hline No catalyst & 0 & 0 & 0 & 0 \\
MAN & 0 & 0 & 0 & 0 \\
2S/MAN & 3.52 & 80.4 & 0.86 & 19.6 \\
5S/MAN & 3.18 & 81.1 & 0.74 & 18.9 \\
10S/MAN & 2.85 & 83.6 & 0.56 & 16.4 \\
15S/MAN & 6.08 & 59.3 & 4.17 & 40.7 \\
& & & & \\
2NbA/MAN & 3.39 & 84.3 & 0.63 & 15.7 \\
5NbA/MAN & 3.49 & 82.9 & 0.72 & 9.1 \\
10NbA/MAN & 1.83 & 91.0 & 0.18 & 18.7 \\
15NbA/MAN & 3.73 & 81.3 & 0.86 & \\
\hline
\end{tabular}




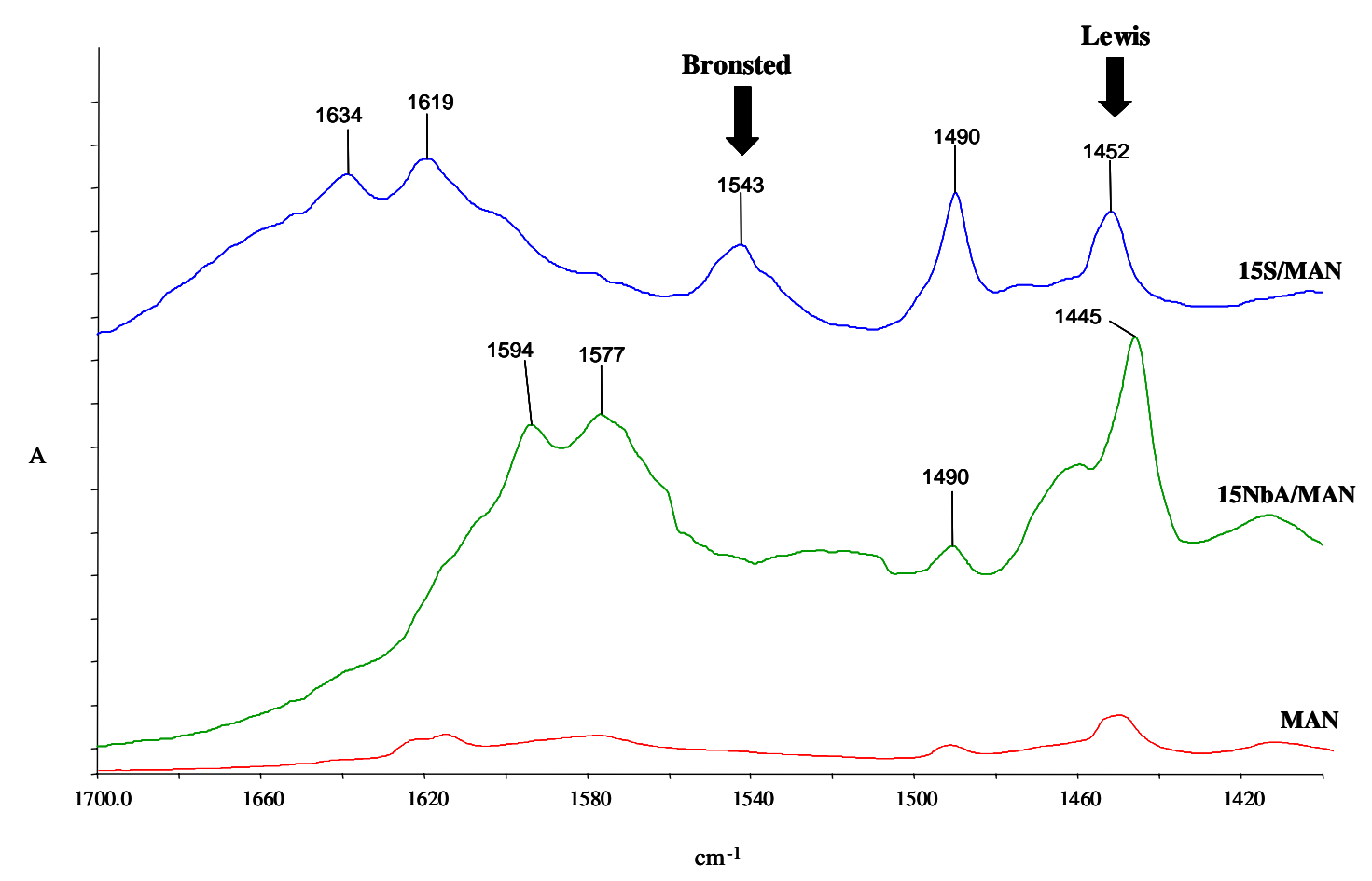

Figure 1: The FTIR spectrum of samples MAN, 15S/MAN and 15NbA/MAN after desorption for $1 \mathrm{~h}$ at $150^{\circ} \mathrm{C}$.

MAN with a loading as low as $2 \%$ of sulfuric acid, produced both monobutylated and dibutylated. This is in agreement with report by Mekhemer et al. [7] which reported that the introduction of a small amount of sulfur compounds onto metal oxides enhanced remarkably the acidic properties of the oxides, regardless of the types of the introduced sulfur compounds. So even though only $2 \%$ of sulfuric acid was loaded to the mesoporous alumina, the increase in the acidity was obvious and significant. The trend of the yield of both the dibutylated and mono butylated products corresponding to the niobic acid loading percent showed no significant differences in the yields produced by each of the samples. Theoretically, the activity of the catalyst should increase with increasing niobium loading on the alumina. However, the results of the catalytic activity contradict with the theory. The results could be caused by the agglomeration among the $\mathrm{Nb}_{2} \mathrm{O}_{5}$ particles, thus lowering the amount of active sites on the surface of the catalyst. In order to confirm this finding, the morphology of sample 15NbA/MAN was investigated using FESEM. 

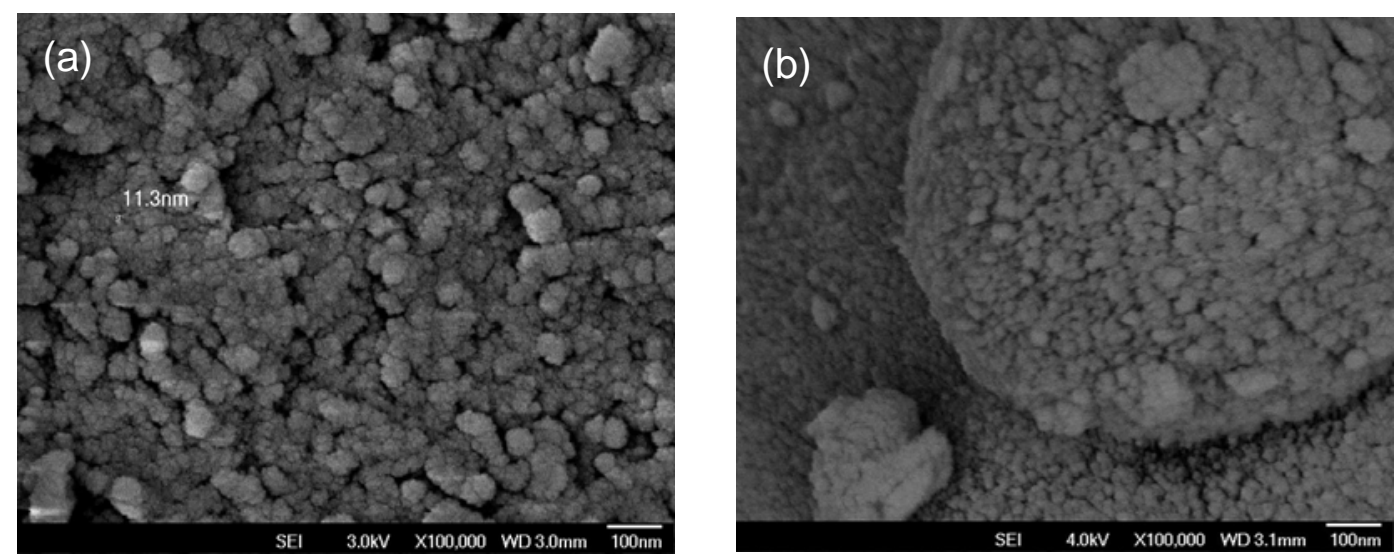

Figure 2: FESEM image of samples (a) MAN and (b) 15NbA/MAN magnified by 100,000 times.

Figure 2 shows the FESEM images for samples MAN and 15NbA/MAN magnified by 100,000 times. For sample MAN, a uniform distribution of particles can be seen. Sample 15NbA/MAN on the other hand, showed that aggregation among the particles occurred. EDX analysis was also carried out for sample 15NbA/MAN. EDX results (Table 2) show that the amount of niobium species in the sample was higher than aluminium, despite the fact that the amount of aluminium should be higher than niobium. This proved that high loading of niobic acid on mesoporous alumina will leads to agglomeration of the particles, which explains the catalytic testing results.

Table 2: EDX results for sample 15NbA/MAN

\begin{tabular}{cc}
\hline Element & Atomic \% \\
\hline Aluminium & 6.62 \\
Niobium & 11.88 \\
Oxygen & 52.06 \\
Carbon & 29.44 \\
\hline
\end{tabular}

The yield of both of the monobutylated and dibutylated products was higher when mesoporous alumina incorporated with sulfuric acid was used as the catalyst. The same pattern was observed when the reusability tests of the catalysts were carried out. Table 3 shows the percent of the yield of the reused catalysts relative to the yield obtained from first time utilization At $2 \%$ loading, both 2S/MAN and 2NbA/MAN did not manage to produce any dibutylated product. However, monobutylated resorcinol can still be obtained using 2S/MAN, even though at a reduced amount. None of the catalysts impregnated with niobic acid were active in the production of dibutylated resorcinol in the reusability test. This could be caused by the change of active sites in the Nb species. According to Braga et al. [8] acidity of the catalyst depends strongly on the $\mathrm{Nb}$ species present. When changes in the $\mathrm{Nb}$ species occur, the $\mathrm{Nb}$ species that present may not be active anymore. Although the amount of yield was decreased, all three 5S/MAN, 10S/MAN and 15S/MAN remained active in the production of both dibutylated and monobutylated 
resorcinol. By comparison with S/MAN and NbA/MAN, the alumina incorporated with sulfuric acid was more active in the alkylation of resorcinol with tert-butyl methyl ether. This is further supported by the results from pyridine-FTIR (Figure 1). Results obtained by pyridine adsorption on pure mesoporous alumina show only the presence of Lewis type acidity. As expected, the FTIR results given in Figure 1 confirmed the absence of Brönsted type acidity with the absence of adsorption band near $1540 \mathrm{~cm}^{-1}$, characteristics of Brönsted acid sites, whereas the characteristics band at $1451 \mathrm{~cm}^{-1}$ that correspond to the vibration of pyridine in sites Lewis type are present. As for sample 15S/MAN and 15NbA/MAN, it is clearly shown that the peak corresponding to Brönsted acid sites at $1540 \mathrm{~cm}^{-1}$ is larger for sample $15 \mathrm{~S} / \mathrm{MAN}$ as compared to that of sample 15NbA/MAN. This confirms that even though the loading percents were the same, sulfuric acid is the better source for creating Brönsted acidity on mesoporous alumina. The incorporation of both sulfuric acid and niobic acid also increased the amount of Lewis acid sites on mesoporous alumina.

Table 3: Reuse of the catalysts for alkylation of resorcinol with MTBE

\begin{tabular}{lcc}
\hline \multirow{2}{*}{ Sample } & \multicolumn{2}{c}{ Yield (\%) } \\
\cline { 2 - 3 } & 4-tertbutylresorcinol & 4,6-di-tertbutylresorcinol \\
\hline 2S/MAN & 12.2 & 0 \\
5S/MAN & 80.5 & 58.1 \\
10S/MAN & 145.6 & 196.4 \\
15S/MAN & 70.9 & 35.7 \\
& & \\
2NbA/MAN & 0 & 0 \\
5NbA/MAN & 0 & 0 \\
10NbA/MAN & 23.5 & 0 \\
15NbA/MAN & 14.2 & 0 \\
\hline
\end{tabular}

\section{Conclusion}

The present study was aimed at understanding the reactivity of incorporated niobic acid and sulfuric acid on mesoporous alumina nanoparticles in the alkylation of resorcinol with tert-butyl methyl ether. The amount of products obtained was higher when sulfated mesoporous alumina nanoparticles was used as the catalyst as compared to mesoporous alumina nanoparticles incorporated with niobic acid. The reusability test also showed that the acid sites created by sulfuric acid were more stable and S/MAN remains active in the alkylation of resorcinol. It indicates that sulfuric acid has created a more stable and higher strength of Bronsted acidity in alumina as compared to niobic acid.

\section{Acknowledgements}

We gratefully acknowledge funding from The Ministry of Higher Education, Malaysia, under Fundamental Research Grant Scheme no.78076 and National Science Fellowship for supporting this research. Special thanks also to Ibnu Sina Institute, UTM for the research facilities. 


\section{References}

[1] C. DeCastro, E. Sauvage, M.H. Valkenberg and W.F Hölderich, Journal of Catalysis, 196 (2000) 8694.

[2] K. Smith, Z. Zhenhua, P. K.G. Hodgson (1998). Journal of Molecular Catalysis A: Chemical. 134. 121-128.

[3] J. Čejka, Applied Catalysis A: General, 254 (2003) 327-338.

[4] J. Aguado, J. M. Escola, M. C. Castro, B. Paredes, Applied Catalysis A: General, 284 (2005) 47-57.

[5] D. Prasetyoko, Z. Ramli, S. Endud, H. Nur, Materials Chemistry and Physics. 93 (2005) 443-449.

[6] E. P. Ng, H. Nur, M. N. M. Muhid, H. Hamdan, Catalysis Today, 114 (2006) 257-262.

[7] G. A. H. Mekhemer, H. A. Khalaf, S. A. A. Mansour, A. K. H. Nohman, Monatshefte für Chemie, 136 (2005) 2007-2016.

[8] V. S. Braga, J. A. Dias, S. C. L. Dias, J. L. De Macedo, Chemistry of Materials. 17(3) (2005) 690-695. 